\title{
Perbandingan Algoritma Naïve Bayes Classifier Dan Algoritma Decision Tree Untuk Analisa Sistem Klasifikasi Judul Skripsi
}

\author{
Rasi Nuraeni ${ }^{1}$, Aso Sudiarjo ${ }^{2}$, Randi Rizal ${ }^{3}$ \\ ${ }^{1,2,3}$ Teknik Informatika, Universitas Perjuangan Tasikmalaya, Jl. Peta No. 177 Kota Tasikmalaya 46115, Indonesia \\ Irasinur@gmail.com, ${ }^{2}$ asosudiarjo@unper.ac.id, ${ }^{3}$ randirizal@unper.ac.id
}

INFORMASI ARTIKEL

\begin{tabular}{l} 
Sejarah Artikel: \\
Diterima Redaksi: \\
Revisi Akhir: \\
Diterbitkan Online: \\
KATA KUNCI \\
\hline Analisis Sistem, \\
Sistem Klasifikasi, \\
Algoritma Decision Tree, \\
Algoritma Naïve Bayes Classifier, \\
Rapidminer
\end{tabular}

KORESPONDENSI

Telepon: 085320132014

E-mail: randirizal@unper.ac.id

\begin{abstract}
This study examines the comparison of thesis title classification using the Naive Bayes Classifier algorithm and the Decision Tree algorithm. The purpose of this study is to compare two algorithms in classifying thesis titles in the Informatics Engineering study program at Universitas Perjuangan Tasikmalaya. The process of collecting data is done by means of literature studies and similar previous research literature. The results of data collection were analyzed using the nave Bayes classifier algorithm and decision tree algorithm with the use of rapidminer tools. The results of this study found a significant accuracy comparison with $80.33 \%$ accuracy for the yahoo nave bayes classifier and $60.33 \%$ for the decision tree algorithm from 55 thesis title data used with 3 types of categorization, namely systems and information technology, visualization and intelligent computers, and engineering and computer networks.
\end{abstract}

\section{Pendahuluan}

Setiap perguruan tinggi di Indonesia menjadikan skripsi sebagai prasyarat untuk menerima dan menyandang status dan gelar sarjana Strata 1 (S1). Begitu juga skripsi bagi mahasiswa Universitas Perjuangan Tasikmalaya merupakan syarat untuk menyelesaikan pendidikan jenjang Strata 1 (S1) berupa karya tulis ilmiah berisikan penjelasan hasil penelitian yang membahas permasalahan berdasarkan minat mahasiswa terhadap judul skripsi dengan kajian pustaka dari penelitian sebelumnya, hasil observasi, hasil eksperimen para ahli. Penyusunan skripsi dilakukan oleh mahasiswa dengan bimbingan dari dosen pembimbing skripsi yang diakhiri dengan pertanggungjawaban pada sidang akhir.

Menurut Siti Aisyah Rahayu [1] skripsi adalah karya tulis ilmiah yang disusun oleh mahasiswa sebagai tugas akhir dalam studi formalnya di perguruan tinggi sesuai dengan bidang studi yang diminatinya berdasarkan penelitian atau studi kepustakaan. Penelitian yang membahas algoritma klasifikasi sudah banyak dilakukan. Sebagai contoh penerapan algoritma naive bayes classifier dalam pencarian nilai probabilitas tertinggi dan paling tepat untuk klasifikasi data uji. Menurut penjelasan [2],[3],[4] algoritma naive bayes classifier dikemukakan oleh Thomas Bayes sebagai metode machine learning dengan pemanfaatan perhitungan statistik dan probabilitas.

Contoh lain metode dengan teknik klasifikasi yaitu algoritma decision tree dengan implementasi pada data mining. Metode pohon keputusan (decision tree) menggambarkan aturan yang berasal dari fakta untuk menggali data dan mencari hubungan antara variable input dengan variable target pada pengolahan data sehingga menghasilkan informasi [5]. Secara pengertian komputasi, algoritma classification atau klasifikasi memberikan identitas pada data. Objek dengan satu set fitur, algoritma classifier menetapkan identitas pada objek yang berhubungan sedangkan algoritma clustering berfungsi dalam pengelompokan objek dan mencari hubungan data antar objek [6],[7].

Ruang lingkup pengambilan judul skripsi oleh mahasiswa Teknik Informatika Universitas Perjuangan Tasikmalaya masih tergolong terpaku pada satu kategori yang sama, sehingga dalam penelitian ini dibahas tentang analisa sistem klasifikasi judul skripsi dengan menggunakan perbandingan Algoritma Naïve Bayes Classifier dan Algoritma Decision Tree. 


\section{Ulasan Penelitian Terkait}

Pada penelitian [8] membahas tentang prediksi lama studi mahasiswa dengan kategori lulus tepat waktu atau sebaliknya. Dalam penelitian ini menerapkan metode Naive Bayes dan Decision Tree dengan hasil komparasi tingkat akurasi perhitungan, Naive Bayes adalah 30\% dan metode pohon keputusan adalah 55\% sehingga disimpulkan bahwa Decission Tree memiliki presentase keakuratan yang lebih tinggi. Perbandingan algoritma klasifikasi dalam penelitian [9] menjelaskan tentang klasifikasi penyakit anak dengan algoritma Decision Tree dan Naïve Bayes. Pada penelitian ini dilakukan klasifikasi berdasarkan gejala - gejala yang sering timbul. Dari hasil perbandingan tingkat akurasi, algoritma Decision Tree menghasilkan tingkat akurasi lebih tinggi dibandingkan dengan algoritma Naïve Bayes yaitu tingkat akurasi 90\% berbanding dengan $89.58 \%$.

Komparasi algoritma juga dilakukan pada penelitian [10] dengan membandingan hasil kinerja algoritma C.45 dan Naïve Bayes pada universitas stikubank semarang dalam memprediksi kegiatan penerimaan mahasiswa baru (PMB). Data percobaan yang digunakan pada penelitian ini sebanyak 2133 dan data pengujian sebanyak 533. Tingkat akurasi pada algoritma C45 sebesar $88.74 \%$ lebih tinggi dibandingkan dengan algoritma Naïve Bayes dengan akurasi $87.24 \%$. Pengujian pada penelitian lainnya [11] menggunakan tingkat validasi dengan 10-fold cross validation dan uji t-test. Sehingga algoritma KNN menghasilkan tingkat akurasi sebesar $85 \%$, sedangkan algoritma CHAID memiliki nilai AUC dengan hasil tertinggi sebesar 0.758. Berdasarkan hasil uji t-test dengan dataset blogger bahwa algoritma Naïve Bayes, ID3 dan CHAID menjadikan algoritma dengan performa terbaik dengan tingkat akurasi tinggi. Performa yang kurang baik dihasilkan oleh algoritma $\mathrm{KNN}$ dan $\mathrm{C} 45$ dengan nilai AUC $0,500 \%$.

Pada penelitian sebelumnya yang telah diuraikan memberikan gambaran terhadap peneliti dalam melakukan penelitian terkait perbandingan algoritma klasifikasi yang akan diimplementasikan pada analisa sistem klasifikasi judul skripsi.

\section{Metodologi}

Penerapan metodologi yang dikerjakan pada penelitian ini ada 2 tahap utama yaitu pengumpulan data dan kategorisasi.

\subsection{Metode Pengumpulan Data}

Peneliti melakukan observasi dengan cara pengamatan dan mendatangi langsung objek penelitian untuk mendapatkan data-data yang dijadikan sebagai bahan penelitian. Objek penelitian dalam hal ini adalah perpustakaan Universitas Perjuangan Tasikmalaya. Selain itu peneliti mengumpulkan data dengan cara mengambil dari berbagai media seperti jurnal, e-book, dan internet yang dijadikan sebagai bahan tinjauan pustaka dan acuan pemecahan masalah dalam penelitian. Kajian Pustaka dilakukan untuk mempelajari penelitian terdahulu yang memilik bahasan yang sejenis dalam rangka pencarian gap penelitian.

\subsection{Metode Kategorisasi}

Pada metode kategorisasi terdapat 2 folder yaitu folder training dan folder test. Selain itu terdapat lima proses diantaranya extraction data, text pre-processing, feauture selection, feature extraction, dan classification stage. Dimana didalam tahapan ini terdapat lima proses, yaitu sebagai berikut:

a. Extraction Data adalah membaca dan mengartikan atau menerjemahkan input data set judul skripsi agar objek tersebut dimengerti oleh system.

b. Text pre-processing adalah permulaan metode untuk menyiapkan teks dan mengolahnya menjadi data lebih lanjut. Proses tokenisasi dilakukan setelah data ditransmisikan berdasarkan spasi dan huruf sehingga menghasilkan token - token yang difilter dan dicatat hasilnya dengan nilai tf-idf (term frequency inversi document frequency) dan selanjutnya dilakukan proses stemming.

c. Feauture selection bertujuan mengurangi format dari kumpulan teks yang dihasilkan atau menghapus kata - kata yang tidak mendeskripsikan isi dari dokumen sehingga menghasilkan proses klasifikasi yang lebih akurat dan efektif.

d. Feature extraction, pada tahap ini kata - kata yang sering keluar akan di filter sesuai nilai data tf-idf (term frequency-inverse document frequency) yang sudah dihasilkan dari proses sebelumnya. Kata - kata dipilih sesuai aturan - aturan tertentu sehingga melahirkan label index yang akan dijadikan label klasifikasi. Selanjutnya menggunakan Algoritma Naïve Bayes Classifier dan Decision Tree untuk mengolah label index tersebut.

e. Classification Extraction, Fase terakhir dari pengkategorian yakni classification extraction yang menghasilkan kategorisasi berdasarkan data test yang dibentuk, dengan menghasilkan 3 kategori yakni Sistem dan Teknologi Informasi (STI), Teknologi Computer dan Jaringan (TKJ), dan Visualisasi dan Komputasi Cerdas (VKC).

\section{HASIL DAN PEMBAHASAN}

\subsection{Tahap Extraction Dato}

Dalam penelitian ini menggunakan data himpunan judul skripsi Teknik Informatika yang akan diklasifikasin ke dalam beberapa kategori.

\begin{tabular}{lr}
\multicolumn{1}{c}{ TABEL 4.1 KATEGORI KLASIFIKASI JUDUL SKRIPSI INFORMATIKA } \\
\hline \multicolumn{1}{c}{ Keterangan } & Skala Data \\
\hline $1=$ sistem dan teknologi informasi & Nominal \\
$2=$ visualisasi dan komputer cerdas & \\
$3=$ teknik dan komputer jaringan &
\end{tabular}

Tabel 4.2 adalah sampel data judul skripsi Teknik Informatika yang telah diklasifikasikan berdasarkan kategori di atas.

Untuk tujuan mempermudah pencarian dan pengarsipan data, maka pengklasifikasian ini dapat dilakukan dengan klasifikasi berbasis kategori judul skripsi. Salah satu metode yang sering digunakan adalah text mining, berfungsi untuk menentukan pola dalam sebuah teks sehingga dapat digunakan dalam tujuan 
tertentu. Dalam penelitian ini, text mining berguna dalam proses pengklasifikasian judul skripsi teknik informatika Universitas Perjuangan Tasikmalaya.

\begin{tabular}{|c|c|c|}
\hline No & Judul Skripsi & Kategori \\
\hline 1. & $\begin{array}{l}\text { Sistem pendukung keputusan } \\
\text { pemilihan penerimaan bantuan dana } \\
\text { desa }\end{array}$ & $\begin{array}{l}\text { sistem dan teknologi } \\
\text { informasi }\end{array}$ \\
\hline 2. & $\begin{array}{l}\text { Pengembangan sistem rekomendasi } \\
\text { buku di perpustakaan universitas } \\
\text { perjuangan menggunakan } \\
\text { pendekatan collaborative filtering }\end{array}$ & $\begin{array}{l}\text { sistem dan teknologi } \\
\text { informasi }\end{array}$ \\
\hline 3. & $\begin{array}{l}\text { Sistem kendali dan monitoring pada } \\
\text { rumah pintar berbasis internet of } \\
\text { things (IoT). }\end{array}$ & $\begin{array}{l}\text { visualisasi dan } \\
\text { komputer cerdas }\end{array}$ \\
\hline 4. & $\begin{array}{l}\text { Aplikasi media pembelajaran bangun } \\
\text { ruang menggunakan augmented } \\
\text { reality berbasis android dengan } \\
\text { metode addie }\end{array}$ & $\begin{array}{l}\text { visualisasi dan } \\
\text { komputer cerdas }\end{array}$ \\
\hline 5. & $\begin{array}{l}\text { Penerapan keamanan } r \begin{array}{l}\text { jaringan } \\
\text { menggunakan dynamic } \\
\text { configuration }\end{array} \text { protokol snooping } \\
\text { dengan metode action research }\end{array}$ & $\begin{array}{l}\text { teknik dan komputer } \\
\text { jaringan }\end{array}$ \\
\hline 6. & $\begin{array}{l}\text { Pengembangan barcode reader } 2 \mathrm{~d} \\
\text { untuk mendukung komunikasi tanpa } \\
\text { kabel }\end{array}$ & $\begin{array}{l}\text { teknik dan komputer } \\
\text { jaringan }\end{array}$ \\
\hline
\end{tabular}

\subsection{Tahap Text pre-processing}

Otomatisasi proses komputerisasi sangat dipengaruhi oleh struktur data yang baik. Dalam text mining, data informasi yang tidak terstruktur akan digali dan dianalisa dalam proses pencarian pola tertentu. Sehingga diperlukan proses dalam perubahan bentuk menjadi data terstruktur berupa nilai - nilai numeric yang sesuai dengan kebutuhan untuk pengolahan data mining. Tahapan proses ini disebut text preprocessing agar sumber data yang dihasilkan dapat diproses secara lebih lanjut dan menyeluruh. Berikut adalah tahapan proses text preprocessing yang diterapkan dalam penelitian ini :

\section{Tahap Tokenizing}

Tokenizing merupakan proses pengurangan string input yang bersumber pada kata penyusunnya dengan mengabaikan karakter yang dapat dianggap sebagai tanda baca. Gambar 1 menjelaskan tentang tahapan tokenizing.

\begin{tabular}{|l|}
\hline PERBANDINGAN \\
ALGORITMA NAÏVE BAYES \\
CLASSIFIER DAN \\
DECISION TREE UNTUK \\
ANALISA SISTEM \\
KLASIFIKASI JUDUL \\
SKRIPSI MENGGUNAKAN \\
RAPID MINER
\end{tabular}

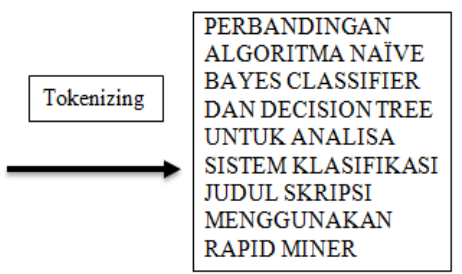

GAMBAR 1. TAHAP TOKENZING

\section{Tahap Filtering}

Filtering merupakan proses pengambilan kata penting dan mengabaikan kata yang dianggap tidak berdampak pada proses klasifikasi. Proses ini menggunakan algoritma stopword / stoplist yang merupakan kata - kata tidak bersifat uraian dan dapat dibuang dengan metode bag-of-words. Gambar 2 menjelaskan tentanf tahapan filtering.

\begin{tabular}{|l|l|l|}
\hline PERBANDINGAN & ANALISA & \\
ALGORITMA & SISTEM & ALGORITMA \\
NAÏVE & KLASIFIKASI & NAIIVE \\
BAYES & JUDUL & BAYES \\
CLASSIFIER & SKRIPSI & CLASSIFIER \\
DAN & MENGGUNAKAN & DECISION \\
DECISION & RAPID & TREE \\
TREE & MINER & KLASIFIKASI \\
UNTUK & & RAPID \\
\hline
\end{tabular}

GAMBAR 2. TAHAP FILTERING

\section{Tahap Case Folding}

Tahap ini merombak seluruh text menjadi lowercase atau dalam bentuk huruf kecil. Dan karakter selain huruf dieliminasi dan dianggap delimiter seperti terlihat pada gambar 3 .

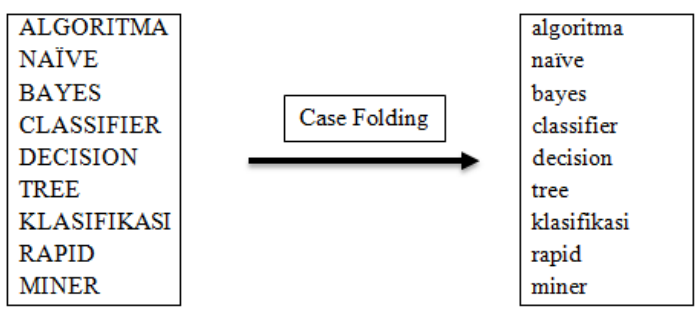

GAMBAR 3. TAHAP CASE FOLDING

\subsection{Algoritma Nä̈ve Bayes Classifier}

Setelah melakukan input data ke tools Rapid Miner repository, dapat dilakukan analisis pengklasifikasian judul skripsi menggunakan algoritma Nä̈ve Bayes seperti langkah-langkah berikut :

1. Memanggil data yang telah disimpan dalam repository.

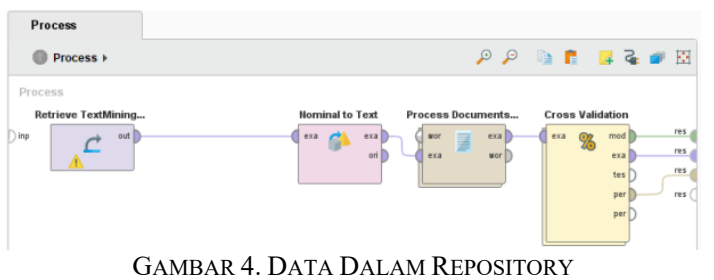

2. Proses data preprocessing dengan perintah Process Documents from Data yang memuat seluruh preprocessing.

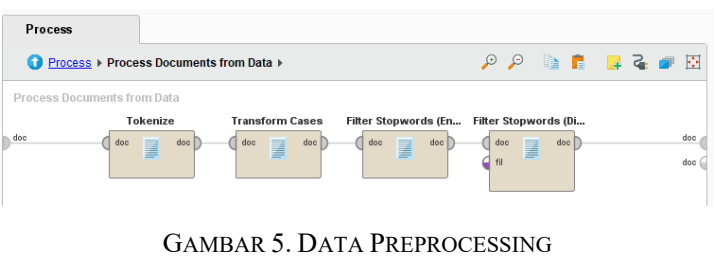

3. Pada bagian Cross Validation, dilakukan pembagian data menjadi data training dan data testing. Karena menggunakan algoritma naïve bayes maka penyusunan lembar proses dilakukan seperti berikut:

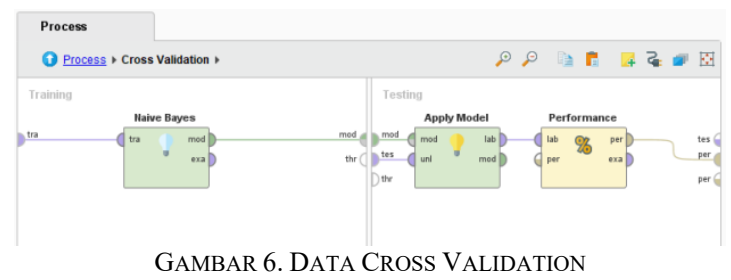


4. Hasil Klasifikasi

Data hasil klasifikasi dengan menggunakan algoritma naïve bayes seperti pada gambar 7 .

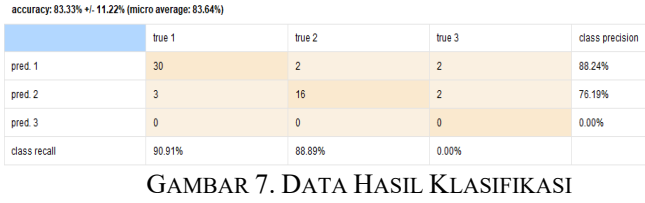

Diperoleh hasil akurasi untuk algoritma naïve bayes sebesar $83.33 \%$. Artinya sistem dapat mengklasifikasikan judul skripsi Teknik Informatika berdasarkan kategorinya sejauh $83.33 \%$.

5. Adapun nilai-nilai pengukuran kualitas kategori yang diperoleh di atas, dapat dihitung menggunakan rumusan sebagai berikut :

a. Accuracy

$$
\begin{aligned}
& \text { Accuracy (Micro Ave. })= \\
& \frac{t p+t n}{(t p+t n+f p+f n)} \times 100 \% \\
& \text { Accuracy (Micro Ave. })=\frac{30+16}{(30+16+6+3)} \times 100 \% \\
& \text { Accuracy (Micro Ave. })=83.636363= \\
& 83.64 \%
\end{aligned}
$$

b. Precision dan Recall

Precision dan Recall diterapkan sebagai perhiturngan berapa banyak informasi benar yang dihasilkan oleh sistem dan mengukur berapa banyak informasi relevan yang diekstraksi oleh sistem tersebut.

$$
\begin{aligned}
& \text { Precision }=\frac{t p}{(t p+f p)} \\
& \text { Recall }=\frac{t p}{(t p+f n)}
\end{aligned}
$$

TABEL 4.3 TABEL HASIL PRECISION DAN RECALL

\begin{tabular}{lccccc}
\hline Kategori & Tp & Fp & Fn & Precision & Recall \\
\hline $\begin{array}{l}\text { Sistem dan } \\
\text { Teknologi } \\
\text { Informasi }\end{array}$ & 30 & 4 & 3 & 0.8824 & 0.9090 \\
\hline $\begin{array}{l}\text { Visualisasi } \\
\text { dan }\end{array}$ & 16 & 4 & 2 & 0.7619 & 0.8889 \\
$\begin{array}{l}\text { Komputer } \\
\text { Cerdas }\end{array}$ & & & & & \\
\hline $\begin{array}{l}\text { Teknik dan } \\
\text { Komputer }\end{array}$ & 0 & 0 & 4 & 0 & 0 \\
Jaringan & Total & & & $\mathbf{0 . 5 4 8 1}$ & $\mathbf{0 . 5 9 9 3}$ \\
\hline
\end{tabular}

\subsection{Algoritma Decision Tree}

Setelah melakukan input data ke Rapid Miner repository, dapat dilakukan analisis pengklasifikasian judul skripsi menggunakan algoritma Decision Tree seperti langkah-langkah berikut:

1. Memanggil data yang telah disimpan dalam repository.

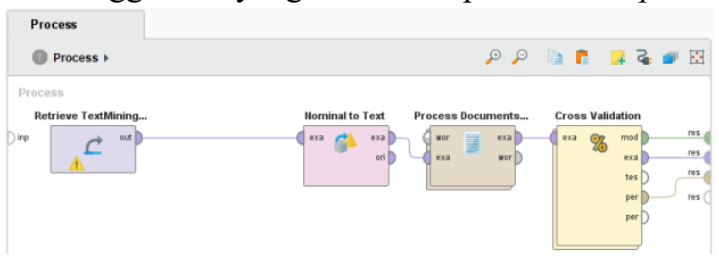

GAMBAR 8. DATA DALAM REPOSITORY
2. Lakukan data preprocessing dengan perintah Process Documents from Data yang memuat seluruh preprocessing

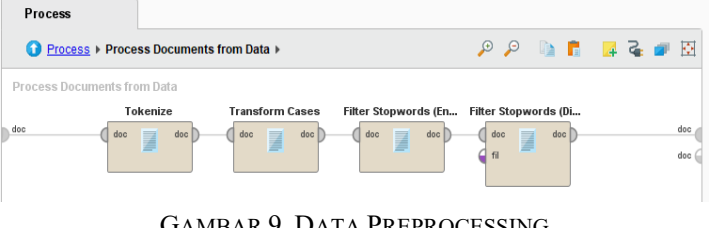

GAMBAR 9. DATA PREPROCESSING

3. Pada bagian Cross Validation, bagi data menjadi data training dan testing. Karena menggunakan algoritma decision tree maka penyusunan lembar proses dilakukan seperti berikut:

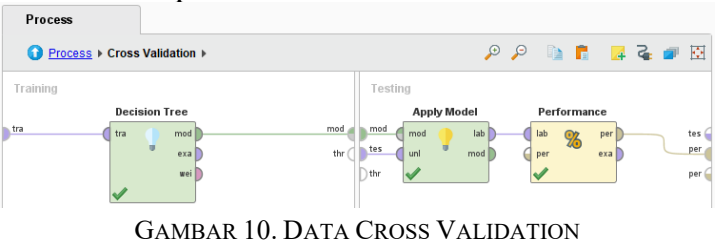

4. Hasil Klasifikasi

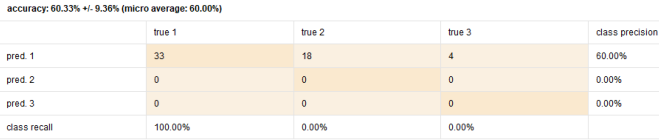

GAMBAR 11. DATA HASIL KLASIFIKASI

Diperoleh hasil akurasi untuk algoritma decision tree sebesar $60.33 \%$. Artinya sistem dapat mengklasifikasikan judul skripsi Teknik Informatika berdasarkan kategorinya sejauh $60.33 \%$.

5. Grafik (Tree) sebagai visualisasi hasil klasifikasi

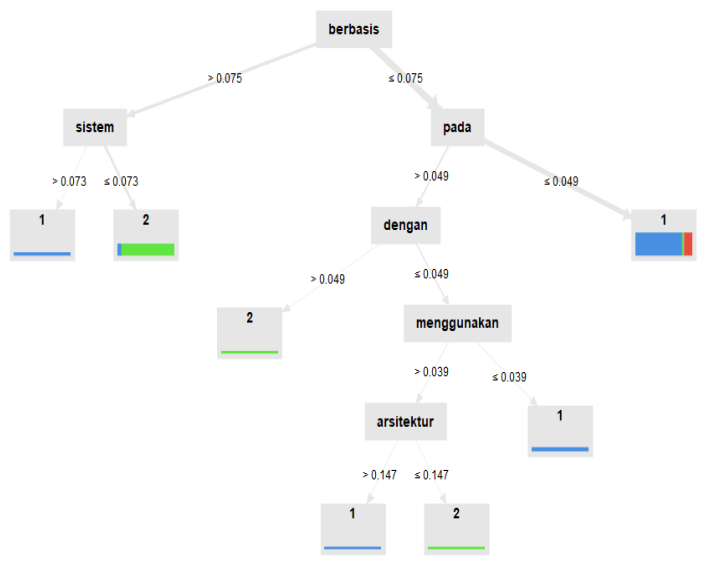

GAMBAR 12. DATA GRAFIK HASIL KLASIFIKASI

6. Adapun nilai-nilai pengukuran kualitas kategori yang diperoleh di atas, dapat dihitung menggunakan rumusan sebagai berikut :

a. Accuracy

Accuracy (Micro Ave. $)=$

$\frac{t p+t n}{(t p+t n+f p+f n)} \times 100 \%$ 
Accuracy (Micro Ave. $)=$

$\frac{33}{(33+0+22+0)} \times 100 \%$

Accuracy (Micro Ave. $)=0.60=60.00 \%$

b. Precision dan Recall

Precision dan Recall diterapkan sebagai perhiturngan berapa banyak informasi benar yang dihasilkan oleh sistem dan mengukur berapa banyak informasi relevan yang diekstraksi oleh sistem tersebut.

$$
\begin{aligned}
& \text { Precision }=\frac{t p}{(t p+f p)} \\
& \text { Recall }=\frac{t p}{(t p+f n)}
\end{aligned}
$$

TABEL 4.3 TABEL PRECISION DAN RECALL ALGORITMA DECISION TREE

\begin{tabular}{lccccc}
\hline Kategori & Tp & Fp & Fn & Precision & Recall \\
\hline $\begin{array}{l}\text { Sistem dan } \\
\text { Teknologi Informasi }\end{array}$ & 33 & 22 & 0 & 0.6000 & 1 \\
$\begin{array}{l}\text { Visualisasi dan } \\
\text { Komputer Cerdas }\end{array}$ & 0 & 0 & 18 & 0 & 0 \\
\hline $\begin{array}{l}\text { Teknik dan } \\
\text { Komputer Jaringan }\end{array}$ & 0 & 0 & 4 & 0 & 0 \\
\hline Total & & & & $\mathbf{0 . 2 0 0 0}$ & $\mathbf{0 . 3 3 3 3}$ \\
\hline
\end{tabular}

\subsection{Interpretasi Hasil}

Berdasarkan hasil klasifikasi menggunakan kedua algoritma di atas, diperoleh bahwa nilai akurasi algoritma naïve bayes lebih akurat dibandingkan dengan decision tree. Dapat dikatakan penggunaan algoritma naïve bayes lebih baik daripada decision tree untuk jumlah data yang terbatas. Berikut akan dijabarkan masing-masing hasil klasifikasi kedua algoritma tersebut:

TABel 4.3 TABel Perbandingan HaSil KLASIFIKASI AlgORITMA

\begin{tabular}{|c|c|c|}
\hline No. & Naïve bayes classifier & Decision tree \\
\hline 1 & $\begin{array}{l}\text { Dalam proses klasifikasi } \\
\text { diperlukan pembagian data } \\
\text { menjadi dua bagian, yaitu } \\
\text { data training dan data } \\
\text { testing }\end{array}$ & $\begin{array}{l}\text { proses klasifikasi ini juga } \\
\text { diperlukan pembagian data } \\
\text { menjadi dua bagian, yaitu } \\
\text { data training dan data testing. }\end{array}$ \\
\hline 2 & $\begin{array}{l}\text { text prepocessing dengan } \\
\text { beberapa metode yaitu, } \\
\text { tokenizing, filtering, dan } \\
\text { case folding. }\end{array}$ & $\begin{array}{l}\text { text prepocessing dengan } \\
\text { beberapa metode yaitu, } \\
\text { tokenizing, filtering, dan case } \\
\text { folding. }\end{array}$ \\
\hline 3 & $\begin{array}{l}\text { Hasil akhir menyatakan } \\
\text { bahwa penggunaan } \\
\text { algoritma naïve bayes dalam } \\
\text { pengklasifikasian judul } \\
\text { skripsi Teknik Informatika } \\
\text { pada penelitian ini mencapai } \\
\text { tingkat akurasi } 83.33 \% \text {. }\end{array}$ & $\begin{array}{l}\text { Hasil akhir menyatakan } \\
\text { bahwa penggunaan algoritma } \\
\text { decision tree dalam } \\
\text { pengklasifikasian judul } \\
\text { skripsi Teknik Informatika } \\
\text { pada penelitian ini mencapai } \\
\text { tingkat akurasi } 60.33 \% \text {. }\end{array}$ \\
\hline 4 & $\begin{array}{l}\text { Menghasilkan } \\
\text { sebesar } 83.33\end{array}$ & $\begin{array}{l}\text { Menghasilkan } \\
\text { sebesar } 83.33\end{array}$ \\
\hline 5 & $\begin{array}{l}\text { Menghasilkan } \\
\text { sebesar } 0.5481\end{array}$ & $\begin{array}{l}\text { Menghasilkan } \\
\text { sebesar } 0.2\end{array}$ \\
\hline 6 & $\begin{array}{l}\text { Menghasilkan } \\
\text { sebesar } 0.5993\end{array}$ & $\begin{array}{l}\text { Menghasilkan recall sebesar } \\
0.3333\end{array}$ \\
\hline 7 & $\begin{array}{l}\text { Nilai presisi menunjukkan } \\
54.81 \%\end{array}$ & $\begin{array}{l}\text { nilai presisi hanya } \\
\text { menunjukkan } 20.00 \% \text { dimana } \\
\text { hanya seperlima dari } \\
\text { keseluruhan data yang dapat } \\
\text { diklasifikasikan dengan } \\
\text { benar. }\end{array}$ \\
\hline 8 & \begin{tabular}{llr} 
Hasil & \multicolumn{2}{c}{ pengklasifikasian } \\
dengan & algoritma naïve \\
bayes classifier mampu
\end{tabular} & \begin{tabular}{lcr} 
hasil & \multicolumn{2}{c}{ pengklasifikasian } \\
dengan & algoritma & decision \\
tree & tidak & mampu
\end{tabular} \\
\hline
\end{tabular}
NAIVE BAYES DAN DECISION TREE

[6] K. L.Sumathy and M. Chidambaram, "Text Mining: Concepts, Applications, Tools and Issues An Overview," International Journal of Computer Applications, vol. 80, no. 4, pp. 29-32, 2013, doi: 10.5120/13851-1685.

[7] N. T. Romadloni, I. Santoso, and S. Budilaksono, "Perbandingan Metode Naive Bayes, Knn Dan Decision Tree Terhadap Analisis Sentimen Transportasi Krl," Jurnal IKRA-ITH Informatika, vol. 3, no. 2, pp. 1-9, 2019.

[8] I. C. Wibowo, A. C. Fauzan, M. D. P. Yustiana, and F. A. Qhabib, "Komparasi Algoritma Naive Bayes dan Decision Tree Untuk Memprediksi Lama Studi Mahasiswa," ILKOMNIKA: Journal of Computer Science and Applied Informatics, vol. 1, no. 2, pp. 65 74, 2019.

[9] S. Bahri, D. Marisa Midyanti, R. Hidayati, J. Sistem Komputer, and F. Mipa, "Perbandingan Algoritma Naive Bayes dan C4.5 Untuk Klasifikasi Penyakit Anak," Seminar Nasional Aplikasi Teknologi Informasi (SNATi), pp. 24-31, 2018.

30 Rasi Nuraeni 
[10] N. Yahya and A. Jananto, "Komparasi Kinerja Algoritma C.45 Dan Naive Bayes Untuk Prediksi Kegiatan Penerimaanmahasiswa Baru (Studi Kasus: Universitas Stikubank Semarang)," Prosiding SENDI, no. 2014, pp. 978-979, 2019.

[11] Ardiyansyah, P. A. Rahayuningsih, and R. Maulana, "Analisis Perbandingan Algoritma Klasifikasi Data Mining Untuk Dataset Blogger Dengan Rapid Miner," Jurnal Khatulistiwa Informatika, vol. VI, no. 1, pp. 20 28, 2018.

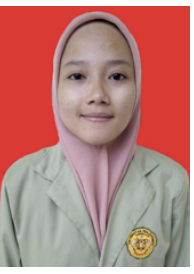

\section{Rasi Nuraeni}

Alumni Program Studi Teknik Informatika, Universitas Perjuangan Tasikmalaya dengan program keahlian Sistem dan Teknologi Informasi. Fokus pada bidang pengolahan data, arsitektur database dan Rapid Miner.

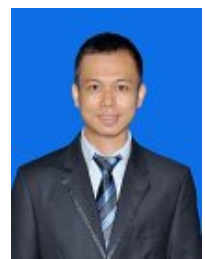

Aso Sudiarjo, M.Kom.

Dosen Teknik Informatika, Fakultas Teknik, Universitas Perjuangan, Tasikmalaya. Aktif dalam bidang Sistem Pengambil Keputusan dan Pengolahan Data Science dan sebagai anggota Asosiasi Perguruan Tinggi Informatika dan Ilmu Komputer (Aptikom) wilayah Jawa Barat.

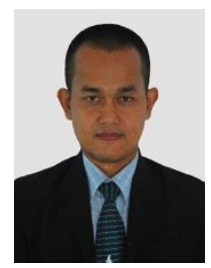

\section{Randi Rizal, M.Kom.}

Dosen sekaligus peneliti dalam bidang teknologi informasi. Praktisi aktif dalam bidang Internet of Things (IoT), security dan digital forensic. Selain sebagai pengajar juga sebagai CEO Sekolah Programmer yuCoding.com yang merupakan sekolah pemrograman pertama di Tasikmalaya dan sebagai anggota Asosiasi Forensik Digital Indonesia (AFDI). 